Running head: Intervention Effects on Coaches' Need Support

\title{
Coaching the Coach: Intervention Effects on Need-Supportive Coaching Behavior and
} Athlete Motivation and Engagement

\author{
Bart Reynders ${ }^{1}$ \\ Maarten Vansteenkiste ${ }^{2}$ \\ Stef van Puyenbroeck ${ }^{1}$ \\ Nathalie Aelterman ${ }^{2}$ \\ Maarten De Backer ${ }^{1}$ \\ Steven Decroos ${ }^{1}$ \\ Jochen Delrue ${ }^{2}$ \\ Gert-Jan De Muynck² \\ Katrien Fransen ${ }^{1}$ \\ Leen Haerens ${ }^{3}$ \\ Gert Vande Broek $^{1}$
}

Funding: This work was supported by Government of Flanders, Department of Sport: B/14197/02-IV2

${ }^{1}$ KU Leuven, Department of Kinesiology,

Tervuursevest 101, 3001 Leuven, Belgium

${ }^{2}$ Ghent University, Department of Developmental, Personality \& Social Psychology

Henri Dunantlaan 2, 9000 Ghent, Belgium

${ }^{3}$ Ghent University, Department of Movement and Sport Science

Watersportlaan 2, 9000 Ghent, Belgium 


\begin{abstract}
The present intervention study examined whether youth sport coaches can be trained in adopting a need-supportive (i.e., autonomy support and structure) coaching style to the benefit of youth athletes' autonomous motivation and engagement. Participants were 43 coaches (33 men, 10 women) and 326 youth athletes (221 boys, 105 girls), active in 12 team or individual sports. Sport coaches were randomly assigned to either a control or intervention condition. The training involved a workshop trajectory spanning four sessions on how to incorporate a (more) need-supportive coaching style. As for coaches' self-reported coaching style, results of multilevel modelling revealed positive effects on autonomy support and control at posttest, and additional effect on structure and control from pre-test to follow-up (i.e., 4 months later) compared to coaches in the control condition. As for athletes' reports, multilevel modelling showed that athletes of coaches in the intervention, relative to those involved in the control group, perceived their coach to be more autonomy-supportive, more structuring, and less chaotic from pre- to posttest, with these effects being more pronounced for athletes of team sports. Further, athletes of coaches in the intervention group reported being more autonomously motivated and more engaged compared to those of coaches in the control group. Overall, the present findings indicate that sport coaches can become more skilled in adopting a need-supportive coaching style, to the benefit of athletes' autonomous motivation and engagement.
\end{abstract}

Key words: sport, autonomy support, structure, Self-Determination Theory, coach education 


\section{Coaching the Coach: Intervention Effects on Need-Supportive Coaching Behavior and}

\section{Athlete Motivation and Engagement}

Although most children participate in sport, a significant percentage lose interest in organized sport during adolescence, due to having a variety of time-conflicting hobbies, other priorities (e.g., school, friends) or, most importantly, a lack of motivation (e.g., Butcher, Lindner \& Johns, 2002). As highly motivated athletes have been found to be more persistent (e.g., Pelletier, Fortier, Vallerand, \& Brière, 2001), the critical question is then how to foster youth athletes' motivation and sustainable engagement. According to Self-Determination Theory (SDT; Ryan \& Deci, 2017), coaches can foster durable forms of motivation and engagement to the extent that they support athletes' basic psychological needs for autonomy, competence, and relatedness (Aelterman, De Muynck, Haerens, Vande Broek, \& Vansteenkiste, 2017; Mageau \& Vallerand, 2003). Therefore, this study will examine (a) whether youth sport coaches can become more skilled in adopting a need-supportive coaching style via a multi-session intervention program and (b) whether such an intervention also yields a positive impact on athletes' autonomous sport motivation (i.e., athletes practicing their sport out of enjoyment and personal commitment) and engagement.

\section{The Motivational Impact of Need-Supportive Coaching}

All youth coaches want their athletes to be highly motivated and engaged during training and competition. Although controlled motivation (i.e., low self-determination) may elicit initial effort-expenditure, to foster long-term persistence more autonomous (i.e., high self-determination) forms of motivation are required (Pelletier et al., 2001), presumably because autonomous motivation contributes to higher and better-quality engagement in sports (Podlog et al., 2015). In this context, SDT (Deci \& Ryan, 2000) postulates that every athlete has three innate basic psychological needs that need to be fulfilled to catalyze autonomous forms of motivation, engagement, and well-being. Specifically, it is important for athletes to 
experience a sense of psychological freedom and volition during sport participation (i.e., need for autonomy), to feel effective in dealing with the environment and in achieving desired outcomes (i.e., need for competence), and to experience a sense of warmth, connected, and bonding with their coach and teammates (i.e., need for relatedness).

Coaches play an essential role in nurturing each of these three basic needs by supporting autonomy, providing structure, and being warm and involved in interactions with their athletes. When being autonomy-supportive, coaches adopt an open, curious and respectful attitude which nurtures athletes' self-initiation and psychological freedom (Soenens \& Vansteenkiste, 2010). An autonomy-supportive coach provides meaningful choices, offers a rationale for decisions and requests, acknowledge athletes' thoughts, feelings and opinions, and supports their initiative taking in their learning process (Mageau \& Vallerand, 2003; Conroy \& Coatsworth, 2007). When offering structure, coaches take the process-oriented development of the athlete as a starting point, thereby providing information and feedback, expressing confidence, and outlining clear and consistent guidelines such that youth athletes feel effective to attain desired outcomes (Deci \& Ryan, 2000; Vansteenkiste \& Soenens, 2015). Finally, a relatedness-supportive attitude is characterized by sincere respect, unconditional acceptance and caring for your athlete as a person (Vansteenkiste \& Soenens, 2015). Coaches can be supportive of athletes' need for relatedness by being available, by showing sincere concern for their well-being - both on and off the field - and by offering comfort if things are going awry, so athletes experience a sense of closeness and care (Deci \& Ryan 2000; Sparks et al., 2015).

At times coaches are challenged to maintain a need-supportive coaching style and may turn to a need-thwarting style, which involves the active interferences of athletes' needs by relying on controlling or chaotic coaching practices. When controlling, coaches act and think from their own perspective and standards; thereby, imposing athletes how to act, think, or feel 
(Soenens \& Vansteenkiste, 2010). When controlling, coaches deny athletes' input and voice, ignore expressions of negative affect, and rely on threatening or pressuring language (Bartholomew, Ntoumanis, \& Thogersen-Ntoumani, 2010; De Muynck et al., 2017). Finally, when chaotic, coaches are unclear or even contradictory about what they require or expect from their athletes and leave their athletes to their own devices; thereby, creating a laissezfaire climate (Delrue et al., 2018).

Multiple studies have provided evidence that specifically general coach need support and coach autonomy support and structure in particular yield benefits for athletes' need satisfaction (De Muynck et al., 2017), autonomous motivation (Amorose \& AndersonButcher, 2007), engagement (Curran, Hill, Hall, \& Jowett, 2014), performance (Gillet et al., 2010; Haerens et al., 2018), persistence (Pelletier et al., 2001) and well-being (Haerens et al., 2018). In contrast, need-thwarting coaching behavior (i.e., control) within the sport context has been linked with controlled motivation and amotivation (Pelletier et al., 2001; Haerens et al., 2018), antisocial behavior (Delrue, et al., 2017), ill-being (Haerens et al., 2018), and burnout (Balaguer et al., 2012).

\section{Need-supportive Coaching in Youth Sport}

While the above studies demonstrated the benefits of need-supportive coaching, not all coaches may be aware or convinced that this approach is beneficial. A number of factors may influence this; including youth coaches' training, their identified role models, and their lack of conceptual understanding of coach autonomy support.

Firstly, although youth sport coaches play a key role in the maintenance of children's motivation and engagement and their development more broadly, in many sport clubs, the role of youth coach is often taken by volunteering former players or parents. At least in Flanders (Belgium), only a limited number of coaches (i.e., 37.58\%) attain official coach certification (Vlaamse Trainersschool, 2018). Moreover, the available educational programs focus 
primarily on sport-specific and methodological aspects of coaching, such as technics, tactics, and didactics; therefore, they only minimally address the motivating role of youth coaches. Although youth coaches may have the necessary skill-related knowledge of the sport concerned, they may not necessarily be capable of transferring this knowledge in a motivating way and therefore maybe largely informed by their personal experiences, beliefs, and orientation. For example, coaches indicate that the way they were coached themselves serves as a model for their own coaching behavior (Lyle, 2002). As a shift towards need-supportive coaching was only recently initiated, many of these coaches, because of their exposure to controlling coaches examples, may still rely upon a more controlling coaching style (Ntoumanis \& Mallet, 2014).

Secondly, youth coaches may not be convinced of the importance of need-supportive coaching as they tend to identify themselves with the coaching practices exemplified by elite sport coaches. Because controlling and highly directive elite sport coaches are often perceived as experts (Cushion, Ford, \& Williams, 2012; Ntoumanis \& Mallet, 2014), youth coaches may hold the belief that such a style is most effective, leading them to "naturally" act in a more controlling way (Ntoumanis \& Mallet, 2014). Also, the belief that a controlling style is effective in the short run may be further strengthened among those youth coaches, who are held accountable for athletes' progression and performance (Reeve, 2009).

Finally, coaches may be reluctant to adopt an autonomy-supportive coaching style as they consider it too soft, and associate it with a 'laissez-faire' climate (Mageau \& Vallerand, 2003; Ntoumanis \& Mallet, 2014). Yet, according to SDT, the provision of autonomy support does not denote a "laissez-faire" attitude, and the provision of autonomy support is not at odds with the provision of structure (Soenens \& Vansteenkiste, 2010). More particularly, to avoid that an autonomy-supportive slips into a too open and even chaotic style (Delrue et al., 2018), coaches have to be aware of the athletes' need to be guided and to receive sufficient structure 
(Mageau \& Vallerand, 2003). As such, intervention studies training coaches to effectively implement both an autonomy-supportive and structuring coaching style, rather than being controlling are needed.

\section{Intervention Research on the Adoption of a Need-supportive Coaching Style}

In spite of their importance, intervention-based studies in the sport context are scarce (see Langan, Blake, \& Lonsdale, 2013 for an overview). For example, using in-depth interviews, Larsen et al. (2015) found that French and Norwegian youth football coaches found a six-hour training program to be particularly helpful in changing their own coaching behavior (i.e., more autonomy support, involvement and structure), and in developing and implementing strategies to stimulate enjoyment, well-being, and long term sport participation. Further, using a small sample of youth football coaches $(N=6)$, Langan et al. (2015) reported that their 12-week SDT-based intervention program promoted coaches' use of rate needsupportive coaching (i.e., autonomy support, structure, involvement). In addition, athletes of coaches in the intervention group reported a decrease in burnout from pre- to postintervention, yet, no changes upon athletes' motivation were found.

Finally, the methodologically strongest study to date was conducted by Cheon et al. (2015) in a heterogeneous group of coaches of Paralympic individual sport athletes. Coaches, who followed a 5-hour training program, were found to become more skilled in autonomysupportive coaching, which resulted in a greater number of Olympic medals obtained. In sum, the intervention work in sports grounded in SDT is still its infancy. Moreover, available intervention studies were not without shortcomings, as they were either limited to a single sport (e.g., Gaelic football, Langan et al., 2015), did not involve a formal quantitative test of the intervention's effectiveness (e.g., Larsen et al., 2015), or only focused on the provision of autonomy support without taking into account features of structure (e.g., Cheon et al., 2015). 


\section{Present Study}

Building on previous work in the PE context (Aelterman et al., 2014) and extending available intervention research in youth sport coaching (e.g., Langan et al., 2015; Larsen et al., 2015), the present study aims to investigate whether youth sport coaches can successfully be trained to adopt an autonomy-supportive and structuring style. In investigating intervention effects on coaches' motivating style, a multi-informant approach is adopted including both coaches' and athletes' reports. Moreover, we aimed to include participants from a broad variety of both team and individual sport types, and to establish both short- (i.e., a 3-week post-test) and long-term (i.e., 4-month follow-up measure) effects.

Two directional hypotheses and one more explorative research question were formulated. First, we hypothesized that coaches in the intervention condition would report to become increasingly autonomy-supportive and structuring from pretest to posttest (Hypothesis 1a), a beneficial outcome which would be maintained four months after the intervention (Hypothesis 1b). Although the intervention program only targeted needsupportive coaching behavior (i.e., autonomy support and structure), a desirable side-effect of the intervention may involve the reduced reliance on controlling and chaotic coaching practices, as this was also the case in a recent study with Paralympic coaches (Cheon et al., 2015). Second, moving beyond coaches' reports, we hypothesized to find positive intervention effects on athletes' perceptions of their coaches' (de-) motivating styles as well as on their autonomous motivation and engagement, which are relevant outcomes in the context of sport coaching (Hypothesis 2).

In a more explorative manner, we examined the potential moderating role of sport type. Given that the study includes a mixed group of youth coaches of team and individual sports, it could be examined whether the intervention yielded equal benefits for both or whether youth coaches of a specific sport type may reap greater benefits. Specifically, given that group 
dynamics inherent in team sports may call for a directive approach, the adoption of an autonomy-supportive coaching style may be more challenging for coaches of team sports. Indeed, past research has found that youth coaches of individual sports grant greater decision power and participation to their athletes (e.g., van de Pol, Kavussanu \& Kompier, 2015), while coaches of team sports tend to adopt a more demanding approach, thereby being more strictly disciplining their athletes (Delrue et al., 2018).

\section{Method}

\section{Participants}

Participants were 43 coaches (33 men, 10 women) and 346 youth athletes ( 233 boys, 110 girls) from 41 sport clubs throughout Flanders (Belgium) who were active in 12 different sports. Fourteen of the 43 coaches $(32.5 \%)$ and their 103 athletes $(30 \%)$ were active in individual sports (i.e., swimming, athletics, tennis, badminton, gymnastics), whereas 29 coaches $(67.5 \%)$ and their 243 athletes (70\%) were active in team sports (i.e., volleyball, basketball, soccer, American football, rugby, hockey, korfball). Coaches were on average 39.16 years old $(S D=12.42$, range $=21-66)$, and were coaching for 13.05 years on average $(S D=10.08$, range $=1-40)$. The age of the athletes ranged between 14 and 24 years with an average of 16.87 years $(S D=1.97)$. The years that athletes were trained by the same coach ranged from 1 to 15 years, with an average of 2.42 years $(S D=2.62)$.

\section{Procedure}

Federations of eight team sports (i.e., basketball, football, handball, hockey, korfball, rugby, soccer and volleyball) and five individual sports (i.e., athletics, badminton, gymnastics, swimming and tennis) were invited by email to participate in this study. In addition, board members of sport clubs were contacted directly and were given information about the study and its protocol. Interested clubs were asked to further distribute this information to their 
youth coaches. Coaches who were interested to participate, registered online thereby providing information regarding their sex, age, sport and name of the club.

To determine sample size (i.e., total number of coaches), we considered previous intervention research which reported moderate to high effect sizes (e.g., Aelterman et al., 2004; Su \& Reeve, 2011). Based on the expectation to find a similar moderate effect (i.e., $\eta 2$ $=.06$; Richardson, 2011) and the traditional .05 threshold for statistical significance, a sample size of $\mathrm{N}=42$ was needed to attain a power of .95 . Researchers of the study assigned 43 coaches to either the control condition ( $N=20$ coaches, $N=169$ athletes) or the intervention condition $(N=23$ coaches, $N=177$ athletes $)$ by adopting a random stratified distribution procedure, thereby securing that coaches of different sex, age, and sport type would be equally distributed across both conditions. The 43 coaches who participated in the study were active in 41 clubs. In the control group (i.e., 20 coaches) there were two pairs of coaches from the same club; therefore, coaches from the same club were included in the same condition (i.e., control group) as they could inform one another about the intervention program when allocated to different conditions.

Following consultation by email or telephone, all coaches and athletes were visited before or after practice to fill out the baseline questionnaires. Prior to our visit, athletes under the age of sixteen were asked to let their parents sign an active informed consent. Athletes who were sixteen years or older signed an active informed consent themselves. Coaches were asked to collect the signed consent forms and hand them over to the research staff at the first measurement occasion. As can be noticed in the timeline depicted in Figure 1, coaches filled out questionnaires at three time points, while athletes filled out questionnaires only at the first two time points. The first measurement (i.e., pretest) took place approximately one week before the start of the intervention program in February (mid-season), whereas the second measurement (i.e., posttest) was completed approximately three weeks after the intervention 
program in May (at the end of the season). Between these two measurement moments (12 weeks), coaches in the intervention group followed an intervention program of 9 weeks, consisting of four workshops on need-supportive coaching, with a three-week interval between each workshop. Coaches in the control group continued their training sessions without intervention and were offered the opportunity to follow the workshops after the end of the study (i.e., after follow-up). Four months after the posttest (i.e., September or the beginning of a new season), a retention test was organized in which coaches filled out the questionnaires for a third time (i.e., follow-up) to examine whether immediate effects would sustain over time. For most of the coaches, this follow-up measure took place at the beginning of a new season. Therefore, athletes were excluded from follow-up assessment as this measurement took place after the summer break on a moment the athletes were no longer trained by the coach who had participated in the intervention.

No coaches dropped out during the intervention from pre- to post-test (100\% retention rate), whereas 63 athletes (35\%) in the intervention group and $53(31 \%)$ in the control group dropped out primarily because of absence, illness or an injury (Figure 2). A chi-square and one-way MANOVA $\left(F(8,330)=1.76, p=.31 ;\right.$ Wilk's $\Lambda=0.972$, partial $\left.\eta^{2}=.03\right)$ indicated that athletes who dropped out did not differ from other athletes in terms of gender $\chi^{2}(1)=.00$, $p=.66)$, type of sports $\left(\chi^{2}(1)=.15, p=.70\right)$, age $(F(1,337)=0.26 ; p=.61)$, baseline measures of engagement $(F(1,337)=2.54 ; p=.12)$, autonomous motivation $(F(1,337)=$ $0.80 ; p=.37)$, controlled motivation $(F(1,337)=3.22 ; p=.08)$, and perceived coach autonomy support $(F(1,337)=3.34 ; p=.07)$, structure $(F(1,337)=3.06 ; p=.06)$, control $(F(1,337)=0.08 ; p=.78)$ and chaos $(F(1,337)=3.14 ; p=.08)$. In total, 230 athletes $(67 \%)$ completed the questionnaires at both pre- and posttest and were retained in the pre- versus post-test comparison. Regarding the follow-up assessment, eight (34\%) coaches of the intervention group and five (25\%) coaches of the control group dropped out because they had 
quit coaching from the previous into a new season. Chi-square and one-way MANOVA ( $F(6$, $35)=0.75, p=.62 ;$ Wilk's $\Lambda=0.887$, partial $\left.\eta^{2}=.11\right)$ tests indicated that coaches who dropped out did not differ from other coaches regarding gender $\left(\chi^{2}(1)=.01, p=.98\right)$ type of sports $\left(\chi^{2}(1)=.03, p=.87\right)$, age $(F(1,40)=1.77 ; p=.19)$, years of experience $(F(1,40)=$ $3.71 ; p=.06)$ and baseline measures of autonomy support $(F(1,40)=0.06 ; p=.81)$, structure $(F(1,40)=0.11 ; p=.74)$, control $(F(1,40)=0.03 ; p=.87)$ and chaos $(F(1,40)=1.07 ; p$ $=.31)$. Therefore, $15(66 \%)$ coaches of the intervention group, and $15(75 \%)$ coaches of the control group were included in the pretest vs. follow-up comparison. A timeline of the study can be found in Figure 1. This study protocol was approved by the Social and Societal Ethics Committee of the research institution.

\section{Need-Supportive Training of Coaches}

The present coaching program entitled 'M-factor' (i.e. Motivation factor), was largely informed by a previous intervention study conducted by Aelterman and colleagues $(2013$ \& 2014) in the context of physical education. The program consisted of four sessions and was developed by a mixed team of SDT-scholars, experienced youth sport coaches and sport psychologists. First, an Initiation Session (i.e., 1.5 hour) including a theoretical and empirical background about the key concepts of SDT, focused on the transfer of knowledge. Two weeks after the initiation session, three more practical, skill-based workshops (i.e., 3 x 3 hours) were organized, as the intervention program focused not only on gathering knowledge, but also, and to a greater extent, on the acquisition of motivating coaching skills. These three workshops were centered on three different topics, that is, "How to adopt a motivating style during training?" (Workshop 1), "How to adopt a motivating style during competition?" (Workshop 2), and "How to introduce and monitor rules in a motivating way?" (Workshop 3). In these workshops, we focused on different components of autonomy-supportive (e.g., promoting dialogue) and structuring coaching (e.g., clarifying expectations). Similar to 
previous work with PE teachers (Aelterman et al., 2014), these components were linked to best practices in different situations, and were illustrated with practical examples and video material. Moreover, the program also included opportunities for group discussion in which coaches could reflect and learn from each other.

The program was delivered by a pair of instructors, involving an experienced youth coach and a sport psychologist familiar with SDT. These instructors tried to act in line with the principles of need-supportive coaching. That is, by using need-supportive strategies themselves, the instructors specifically addressed the needs of the participating coaches; thereby, fostering their motivation to engage in the program (Aelterman et al., 2013). A threeweek interval was left in between two sessions, allowing the coaches to further absorb the acquired knowledge and skills and to apply the proposed coaching strategies in practice. At the beginning of the next workshop time was reserved to reflect on coaches' experiences with implementing these strategies over the past three weeks.

\section{Measures}

Coaches' need-supportive/thwarting behavior. Coaches rated their own needsupportive and need-thwarting behavior using the recently developed Situations-in-Sport Questionnaire (Delrue et al., 2018). The SIS-Q consists of 15 sport-specific vignette-like situations. For each of these vignettes, coaches had to score four different coaching practices, with each of these practices matching either an autonomy-supportive, controlling, structuring, or chaotic coaching style. Coaches rated the extent to which each of these reactions described their own style of coaching on a 7-point Likert scale from 1 (does not describe me at all) to 7 (describes me extremely well). An exemplary situation is 'In the first part of the competition/game your athletes did not play at the level that you expected them to. During the break...' (a) you don't say much, they know what they need to do to get back into the competition (i.e., chaos); (b) you give them a stern talking-to: 'It is up to you now to set this 
right and show what you are worth' (i.e., control); (c) you ask their opinion and afterwards you give them your instructions for the rest of the competition (i.e., autonomy); and (d) you remind them of the instructions you gave them before the competition (i.e., structure). If a situation did not occur before pretest or in-between the two measurement moments, coaches and athletes were asked to hypothetically score this situation as if it would present itself at the moment. Delrue et al. (2018) conducted Multidimensional scaling on the 60 items (4 responses by 15 vignettes) and identified four clusters of items, each representing one specific coaching style (e.g., autonomy support). All of these four coaching styles showed good internal consistencies within the athlete version of the SIS-Q (Delrue et al., 2018) with Cronbach alpha values being, .83 for autonomy support, .86 for structure, .86 for control, and .78 for chaos. Within the current study, internal consistencies at all time points of the subscales ranged from .83 to. 89 for autonomy support, .86 to .91 for structure, .68 to .81 for control, and .59 to .77 for chaos $(M=.79)$.

Athletes were asked to complete the athlete version of the SIS-Q (Delrue et al., 2018) to assess their coaches' need-supportive and need-thwarting behavior. They were asked to rate the same 15 vignettes as in the coach version to which degree the items corresponded to the behavior of their coach on a 7-point Likert scale from 1 (does not describe my coach at all) to 7 (describes my coach extremely well). The original athlete version of the SIS-Q (Delrue et al., 2018) showed good internal consistencies with Cronbach alpha values being, .86 for autonomy support, .87 for structure, .84 for control, and .85 for chaos. Within the present study, Cronbach's alphas at all time points ranged from .81 to.85 for autonomy support, .79 to .85 for structure, .80 to .82 for control, and .74 to .79 for chaos $(M=.81)$.

Athlete motivation. An adapted version of the Behavioral Regulations in Sport Questionnaire (BRSQ: Lonsdale, Hodge, \& Rose, 2008) was used to measure athletes' motivation. In the original validation paper, Lonsdale et al., (2008) provided satisfactory 
evidence for the internal consistency and factorial validity of the BRSQ. The BRSQ was slightly adapted by Assor, Vansteenkiste, and Kaplan (2009), who differentiated between different forms of introjected regulation (i.e., introjection-approach and introjection-avoidance regulation) and limited themselves to including items tapping into general intrinsic motivation instead of its facets (i.e., intrinsic motivation to know, intrinsic motivation to experience stimulation, and intrinsic motivation to accomplish). Congruent with the idea of an underlying self-determination continuum, Assor et al. (2009) reported that the different subscales formed an ordered pattern of correlates, with the Cronbach's alphas ranging from .73 to .84 (Assor, Vansteenkiste and Kaplan, 2009). All items were answered on a 7-point Likert scale ranging from 1 (totally disagree) to 7 (totally agree). For both theoretical reasons (e.g., Ryan \& Deci, 2000) and reasons of parsimony, two composite scores, that is, autonomous and controlled motivation were created (see also Pelletier et al., 2001; Vansteenkiste et al., 2009). Specifically, a composite score of autonomous motivation (e.g., "I participate in my sport because it is part of who I am") was created by averaging the scores of intrinsic, integrated, and identified regulation, while a composite score of controlled motivation (e.g., "I participate in my sport to satisfy people who want me to") was created by averaging the scores of introjected and external regulation (e.g., Vansteenkiste et al., 2009). Internal consistencies of autonomous and controlled motivation at pre- and posttest ranged from 87 to $.92(M=.89)$.

Athletes' self-reported engagement. To assess athletes' self-reported emotional (e.g., "I enjoy learning new things on training \& competition"), cognitive (e.g., "I try to relate what I'm learning to what I already know during training \& competition”), behavioral (e.g., "I try hard to do well during training \& competition") and agentic ("I express my preferences and opinions during training \& competition") engagement, we used 17 items based on the work of Skinner et al. (2009), Reeve (2013), Reeve and Tseng (2011), and Wolters (2004). As previously revealed by Reeve (2003), this set of items have shown good internal consistency, 
with Cronbach's alpha for emotional, cognitive, behavioral and agentic engagement being .91, $.71, .87, .84$, respectively. Items were adjusted to the sport context by changing for example 'Teacher' into 'Coach' and 'Class' into 'Team'. Athletes were asked to rate each item on a 7point Likert scale from 1 (totally disagree) to 7 (totally agree). Although partition of engagement in four components allows looking at someone's behavior in a more detailed and profound way, the four components dynamically intercorrelate within one person in reality (Cheon, Reeve, Lee \& Lee, 2015). Therefore, as the specificity of these subcomponents go beyond the scope of this study, a composite score of the four subcomponents resulted in a total score of athletes' engagement (Cheon, Reeve, Lee \& Lee, 2015: $\alpha=.87$ ). Internal consistencies were .92 and .93 at pre- and posttest, respectively.

\section{Data Analysis}

To test the effect of the intervention program on coaches' self-reported need-supportive and -thwarting behavior (Hypothesis 1a \& b), we performed multilevel regression analyses on the coach data, thereby examining effects across three time points simultaneously. Within these multilevel regression models Time was inserted as a Level 1-predictor and Condition as a Level 2-predictor (as this predictor varies between coaches) with the Time x Condition cross-level interaction reflecting the intervention effect. To unravel this effect across three time points, we further checked for the effects on autonomy support, structure and control from pretest to posttest, from pretest to follow-up, and from posttest to follow-up.

Due to the hierarchical structure of the athlete data (measurements within athletes within coaches), we also used multilevel regression modelling to investigate changes in athletes' perceived need-supportive and need-thwarting coaching style (Hypothesis 1a), athletes' motivation, and engagement (Hypothesis 2). Time was inserted as a Level 1predictor, Condition as a Level 2-predictor (as this predictor varies between athletes) and the intervention effect was analyzed by testing the Time $\mathrm{x}$ Condition cross-level interaction. As 
outlined above, the 43 coaches who participated in the study were active in 41 clubs, with two pairs of coaches being active at the same club. As the number of coaches within each club is rather limited, clubs were not included as a separate level (Maas \& Hox, 2005). A three level model was justified as the intercept-only models (Hox, 2010) displayed significant betweencoach variance for perceived autonomy support (Pretest: .32, $\chi^{2}(1)=67.95$; Posttest: .44, $\chi^{2}(1)$ $=76.59)$, perceived structure (Pretest: $.43, \chi^{2}(1)=105.09$; Posttest: .46, $\chi^{2}(1)=67.86$ ), perceived chaos (Pretest: .28, $\chi^{2}(1)=47.82$; Posttest: $\left..37 \chi^{2}(1)=55.05\right)$, perceived control (Pretest: .37, $\chi^{2}(1)=78.85$; Posttest: .30, $\chi^{2}(1)=48.33$ ), autonomous motivation (Pretest: .15, $\chi^{2}(1)=23.46$; Posttest: $\left..10, \chi^{2}(1)=9.21\right)$, controlled motivation (Pretest: .05, $\chi^{2}(1)=7.74$; Posttest: .05, $\chi^{2}(1)=5.52$ ), and engagement (Pretest: .27, $\chi^{2}(1)=56.29$; Posttest: .25, $\chi^{2}(1)=$ 37.75), all $p$ s $<.001$.

To test for robustness and consistency of the findings of the abovementioned primary main analyses with only complete cases (i.e., without participants who missed one of the measurement moments), we performed sensitivity analyses by additionally analyzing data involving imputed missing values of both athletes and coaches. More specifically, we relied on a Multiple Imputation by chained equations procedure using an iterative Markov chain Monte Carlo (MCMC) method, to replace missing values of participants who failed to attend one of the measurement moments (Azur, Stuart, Frangakis, \& Leaf, 2011; Schafer, 1999). Subsequently, analyses identical to the main analyses that were performed on the complete case data were also conducted on the data including imputed missing values. These results were compared to check for the robustness of findings.

As an ancillary aim, we investigated the potential moderating role of sport type (i.e., team vs. individual sports) by including a three-way interaction between time, condition and sport type as an extra predictor in the multilevel regression models of the main analyses. When a significant Time $\mathrm{x}$ Condition $\mathrm{x}$ Sport Type interaction was found, we used the same 
multilevel regression modelling among subsamples of coaches or athletes within team and individual sports to test effects of the intervention program for individual and team sports separately.

\section{Results}

\section{Preliminary Analyses}

Testing for differences between coaches. First, associations between baseline measures of need-supportive (i.e., autonomy support and structure) and need-thwarting (i.e., control and chaos) coaching behavior and coach characteristics (sex, age, sport type and years of experience) were tested. Four multiple regressions were run to predict coaches' autonomy support, structure, control and chaos with sex, age, sport type and years of experience serving as predictors. These variables did not relate to coaches' autonomy support $(F(4,37)=1.54, p$ $\left.=.21, R^{2}=.14\right)$, structure $\left(F(4,37)=1.07, p=.39, R^{2}=.10\right)$ and chaos $(F(4,37)=0.69, p=$ $\left..60, R^{2}=.07\right)$. However, controlling coaching $\left(F(4,37)=3.08, p<.05, R^{2}=.25\right)$ was predicted by coach gender $(B=-0.56, S E=.23, p<.05)$ and years of experience $(B=0.03, S E$ $=.01, p<.05)$, with male and older coaches being more likely to use a controlling style.

Testing for differences between conditions. We verified whether both the intervention and control group differed regarding coaches' demographics (i.e., sex, sport type, age, and years of experience) and baseline measures (coach- and athlete-reported coaching style, athletes' autonomous and controlled motivation, and athletes' engagement). First, chi-square tests indicated that there were no significant differences between the intervention and control group regarding gender $\left(\chi^{2}(1)=.22, p=.64\right)$ and sport type $\left(\chi^{2}(1)=.11, p=.74\right)$. Next, a oneway MANOVA test with baseline measures of autonomy support $(F(1,41)=0.38 ; p=.54)$, structure $(F(1,41)=0.98 ; p=.33)$, chaos $(F(1,41)=.09 ; p=.77)$, control $(F(1,41)=.05 ; p$ $=.82)$, age $(F(1,41)=0.01 ; p=.92)$ and years of experience $(F(1,41)=0.02 ; p=.88)$ as dependent variables and condition as a fixed factor showed no significant differences between 
the intervention and control group for each of these variables, $F(6,35)=0.25, p=.96$;

Wilk's $\Lambda=0.959$, partial $\eta^{2}=.04$. As for athlete reports, we relied on multilevel regressions to test for baseline measure differences between the two conditions. Chi-square tests showed that none of the dependent variables (i.e., perceived autonomy support, perceived structure, perceived chaos, perceived control, autonomous and controlled motivation, and engagement) differed between the two conditions, all $p s>.19$.

\section{Coach Reports}

Results from the multilevel modeling on coaches' self-reported need-supportive and thwarting coaching across three time points showed that the Condition $\times$ Time interaction was significant for coaches' self-reported autonomy support $(\beta=0.19, S E=.09, p<.05)$, structure $(\beta=0.21, S E=.07, p<.01)$, and control $(\beta=-0.36, S E=.11, p<.01)$, but not for chaos $(\beta=$ $-0.03, S E=.09, p=.72)$. When testing the same multilevel models across three time points with imputed missing values for coaches who dropped out from pretest to follow-up (i.e., 13 coaches) results show analogous interaction effects for autonomy support $(\beta=0.20, S E=.08$, $p<.05)$ and structure $(\beta=0.23, S E=.06, p<.01)$, but not for control $(\beta=-0.11, S E=.12, p$ $=.35)$ and $\operatorname{chaos}(\beta=-0.05, S E=.08, p=.53)$.

To additionally sort out these effects over three time points (pretest, posttest and followup), we further performed multilevel regression modelling to check for the effects on autonomy support, structure and control from pretest to posttest, from pretest to follow-up, and from posttest to follow-up separately.

Shifts from pretest to posttest. Results of the multilevel modelling on coaches' selfreported autonomy-supportive, structuring, controlling and chaotic coaching behavior from pretest to posttest can be found in Table 1. Two of the four condition by time effects were significant, that is, those for autonomy-supportive and controlling coaching behavior, but not for structuring neither chaotic coaching. As can be found in Table 1, a time-related increase in 
autonomy-supportive coaching $(\Delta=.51)$ was found within the intervention group, while coaches in the control group reported a status quo $(\Delta=.03)$. Simple slope analysis showed a trend towards an increase in coaches self-reported autonomy support $(\beta=0.50, S E=.12, p=$ $.15)$ in the intervention group, but not in the control group $(\beta=0.03, S E=.13, p=.86)$. As for controlling coaching, while coaches in the intervention group reduced their controlling coaching style $(\Delta=-.48)$, those in the control group reported a rather status quo $(\Delta=.21)$. In line with this, simple slope analysis showed a trend towards a significant decrease in controlling coaching in the intervention group $(\beta=-0.48, S E=.15, p=.14)$, which was not found in the control group $(\beta=0.21, S E=.11, p=.33)$. However, as significant interaction effects for both autonomy support and control were found for the complete sample $(N=43)$, it should be noted that the limited number of coaches within each group (i.e., 23 coaches in the intervention group; 20 coaches in control group) may account for why simple slopes in the intervention group failed to reach significance.

As no coaches dropped out (i.e., no missing values) from pretest to posttest, we did not imputed missing values to perform sensitivity analyses.

Shifts from pretest to follow-up. To test for sustainable effects on coaches' needsupportive behavior, we relied on separate multilevel modelling for coaches' need-supportive and need-thwarting coaching behavior from pretest to follow-up. As can be seen in Table 2, Condition $\mathrm{x}$ Time effects were no longer significant for autonomy support, while this effect remained significant in the case of coach control. However, although coaches in the intervention group reported a decrease in control $(\Delta=-.31)$ from pretest to follow-up and coaches in the control group reported an increase $(\Delta=.40)$, simple slope analysis for both the intervention group $(\beta=-0.14, S E=.09, p=.38)$ and control group $(\beta=0.19, S E=.09, p=$ .28) did not reach significance. Condition $\mathrm{x}$ Time effects were significant for structuring coaching, with coaches in the intervention group reporting an increase in structure from 
pretest to follow-up $(\Delta=.48)$ while no such changes were found in the control group $(\Delta=$ .01). In line with this, simple slope analysis showed a trend towards an increase in structure within the intervention group $(\beta=0.22, S E=.06, p=.16)$, which was not found within the control group $(\beta=-0.01, S E=.05, p=.97)$. As already stated above, while the significant interaction effect provides evidence for the effectiveness of the intervention $(N=30)$, the number of coaches within each group (i.e., 15 coaches in the intervention group; 15 coaches in control group) may be too limited for simple slope analysis to statistically confirm significant changes within each group separately.

As stated before, we imputed missing values of coaches who dropped out from pretest to follow-up (i.e., 13 coaches). In line with complete case analysis, analysis of data including these imputed values showed an interaction effect for structure $(\beta=0.23, S E=.05, p<.01)$, but not for chaos $(\beta=-0.05, S E=.08, p=.53)$, from pretest to follow-up. Regarding selfreported autonomy support, an interaction effect was found $(\beta=0.20, S E=.07, p<.01)$ when imputing missing values. However, presumably because a lack of power (i.e., loss of 13 of 43 coaches who dropped out from pretest to follow-up), this interaction effect failed to reach significance within the primary complete case analysis. Regarding coaches' self-reported control, analysis with imputed data showed no time $\mathrm{x}$ condition effect $(\beta=-0.12, S E=.13, p$ $=.38)$, while complete case analysis did show an interaction effect $(\beta=-0.33, S E=.12, p<$ $.01)$

Shifts from posttest to follow-up. Results of the multilevel modelling on coaches' selfreported autonomy-supportive, structuring, controlling and chaotic coaching behavior from posttest to follow-up can be found in Table 3. A significant Condition x Time effect was found for coaches' self-reported structure from posttest to follow-up. Inspection of the means in Table 3 illustrates that coaches in the intervention group reported an increase in selfreported structure $(\Delta=.36)$, whereas coaches in the control group reported a small decrease 
$(\Delta=-.16)$. However, presumably because of the limited number of coaches within each group (i.e., 15 coaches in the intervention group; 15 coaches in control group) simple slope analysis failed to reach significance in both the intervention group $(\beta=.30, S E=.11, p=.23)$ and control group $(\beta=-0.14, S E=.12, p=.44)$. Furthermore, no significant interaction effects were found for autonomy support, control and chaos from posttest to follow-up.

Analogous to complete case analysis, a significant condition $\mathrm{x}$ time effect was found for coaches' self-reported structure $(\beta=0.46, S E=.15, p<.001)$ from posttest to follow-up, while no interaction effects were found for autonomy support $(\beta=0.07, S E=.15, p=.65)$, control $(\beta=-0.45, S E=.20, p=.07)$, and chaos $(\beta=-0.05, S E=.15, p=.75)$ when performing the same multilevel modeling with imputed missing values.

\section{Athlete Reports}

Perceived coaching behavior. The Time, Condition, and Condition $\mathrm{x}$ Time effects of the multilevel modeling on athletes' perceived need-supportive and -thwarting coaching can be found in Table 4. Results showed that the Condition $\times$ Time interaction was significant for athlete perceived autonomy support, structure, and chaos, but not for control. Follow-up simple slope analysis revealed that athletes' perceived autonomy support increased in the intervention group $(\beta=0.20, S E=.07, p=.002)$, while it remained stable in the control group $(\beta=-0.04, S E=.06, p=.51)$. Athletes' perceived structure also increased in the intervention group $(\beta=0.15, S E=.07, p=.029)$ but decreased in the control group $(\beta=-0.16, S E=.07, p$ $=.017)$. Finally, athletes' perceived chaos remained stable in the intervention group $(\beta=0.02$, $S E=.05, p=.77)$, but increased in the control group $(\beta=0.21, S E=.05, p<.001)$.

Analysis of data including imputed missing values (i.e., participants who failed to attend one of the measurement moments) were consistent with effects or findings obtained by complete case analysis. That is, athletes reported significant Condition $\mathrm{x}$ Time effects on perceived autonomy support $(\beta=0.15, S E=.07, p<.05)$, perceived structure $(\beta=0.20, S E=$ 
$.07, p<.01)$, and perceived chaos $(\beta=-0.13, S E=.05, p<.05)$, but not for perceived control $(\beta=-0.08, S E=.06, p=.16)$.

Motivation and engagement. As can be noticed in Table 5, significant Condition $\times$ Time interaction effects were found for athletes' autonomous motivation and engagement, but not for their controlled motivation. As revealed by simple slope analysis, athletes in the intervention group reported an increase $(\beta=0.16, S E=.07, p<.05)$, while athletes in the control group reported a decrease in autonomous motivation $(\beta=-0.15, S E=.06, p<.05)$. Finally, whereas athletes in the control group reported no significant change in engagement ( $\beta$ $=-0.07, S E=.06, p=.20)$, athletes in the intervention group reported an increase $(\beta=0.25$, $S E=.06, p<.001)$

Analogous to above complete case analysis, analysis of data including the imputed missing values of athletes who missed one of the measurement moments indicated significant interaction effects were found regarding athletes self-reported autonomous motivation $(\beta=$ $0.26, S E=.06, p<.001)$ and engagement $(\beta=0.22, S E=.06, p<.001)$, but not for controlled motivation $(\beta=-0.02, S E=.07, p=.81)$.

\section{The Role of Type of Sports}

By including sport type as an additional between-person predictor in the preceding series of analyses, we explored the potential moderating role of sport type (i.e., team vs. individual sports). Results of the coach reports showed no significant Time x Condition x Sport type interactions across three time points for coaches' self-reported autonomy support $(\beta=0.01$, $S E=.05, p=.91)$, structure $(\beta=0.02, S E=.04, p=.70)$, control $(\beta=0.09, S E=.05, p=.07)$ and chaos $(\beta=0.05, S E=.04, p=.75)$. A similar pattern emerged from separate multilevel analyses, with the three-way interaction failing to reach significance for coach autonomy support, structure, control or chaos from pretest to posttest, from pretest and follow-up, and from posttest to follow-up (all $p s>.05$ ). Said differently, the self-reported changes in need- 
supportive and need-thwarting coaching style apply to both coaches of individual and team sports.

The pattern of findings looked differently for athletes. Having inserted sport type, sport type by condition, sport type by time, and three-way interaction between time, condition and sport type as additional predictors in the multilevel model, the Time $\mathrm{x}$ Condition $\mathrm{x}$ Sport Type interaction was significant for athlete perceived autonomy support $(\beta=-0.41, S E=.21, p<$ $.05)$ and structure $(\beta=-0.55, S E=.21, p<.01)$, and marginally significant for engagement $(\beta$ $=-0.37, S E=.19, p=.05)$, but not for control $(\beta=-0.27, S E=.20, p=.18)$, chaos $(\beta=0.19$, $S E=.17, p=.26)$, autonomous motivation $(\beta=-0.16, S E=.21, p=.45)$, or controlled motivation $(\beta=0.44, S E=.27, p=.10)$. To further unravel this three-way interaction, in a next step, we tested condition $\mathrm{x}$ time effects for individual and team sport athletes' separately.

Athletes within individual sports reported significant Condition $\mathrm{x}$ Time interaction effects for perceived autonomy support $(\beta=0.56, S E=.19, p<.005)$, perceived structure $(\beta=0.71$, $S E=.19, p<.001)$, and self-reported engagement $(\beta=0.57, S E=.17, p<.001)$. Simple slope analysis showed that individual sport athletes reported their coaches' autonomy-supportive behavior to increase in the intervention group $(\beta=0.38, S E=.11, p<.001)$, while it remained stable in the control group $(\beta=-0.16, S E=.15, p=.29)$. Athletes' perceived structure also increased in the intervention group $(\beta=0.39, S E=.11, p<.001)$ but decreased in the control group $(\beta=-0.31, S E=.15, p<.05)$. Finally, whereas athletes in the intervention group reported their engagement to increase $(\beta=0.48, S E=.10, p<.001)$, athletes in the control group reported their engagement to remain stable $(\beta=-.10, S E=.14, p=.46)$.

Within the subsample of team sport athletes, multilevel modeling showed a significant Condition $\times$ Time interaction regarding engagement $(\beta=0.20, S E=.09, p<.05)$, but not for autonomy support $(\beta=0.13, S E=.10, p=.19)$, and structure $(\beta=0.14, S E=.11, p=.18)$. Simple slope analysis showed a trend towards a marginal increase in team sport athletes' 
engagement in the intervention group $(\beta=0.13, S E=.07, p=0.07)$, while it remained stable in the control group $(\beta=-0.07, S E=.06, p=.26)$.

\section{Discussion}

Given the multiple advantages of a need-supportive style in fostering durable motivation and engagement (e.g., Amorose \& Anderson-Butcher, 2007; Gillet et al., 2010), researchers have increasingly tested whether socializing agents (e.g., teachers; Aelterman et al., 2014) can be trained in adopting a need-supportive motivating style. Within the sport context, however, intervention-based research grounded in SDT is scarce. The present study aimed to expand the extant literature by investigating youth sport coaches' trainability in adopting a need-supportive style and by examining whether the adoption of a need-supportive coaching style affects athletes' autonomous motivation and engagement.

\section{Coach reports}

The results from coaches' reports showed that the intervention program changed coaches' need-supportive coaching style. More specifically, and in line with previous findings obtained in different domains (e.g., Aelterman, 2014; Langan et al., 2015), coaches in the intervention group reported an increase in self-reported autonomy support compared to those in the control group. However, coaches initially may be more skeptical towards the notion of coach autonomy support, as controlling coaching is often believed to be more effective and controlling coaches are said to have greater expertise (Cushion, Ford, \& Williams, 2012; Ntoumanis \& Mallet, 2014). However, the intervention program was set up in such a way to maximize coaches' experienced need satisfaction. Specifically, trainers delivering the intervention program engaged in autonomy-supportive (e.g. promote dialogue and discussion), relatedness-supportive (e.g. install a positive atmosphere) and structuring (e.g. promote self-reflection) strategies to facilitate the satisfaction of coaches' own psychological needs (Stebbings, Taylor, Spray, \& Ntoumanis, 2012). Moreover, through the provision of 
practical illustrations of coach need support together with the possibility to experiment with the offered need-supportive strategies in between two workshops, coaches' sense of confidence in the use of autonomy-supportive and structuring strategies may have further increased.

Regarding controlling coaching behavior, we suggested the possibility of a desirable side-effect among coaches in the intervention group. That is, due to their strong focus on increasing their need-supportive coaching behavior, coaches may have decreased their controlling style along the way (Cheon et al., 2015). That is, although the reduction of controlling strategies was not a central goal of the workshops, by investing greater effort and time in using autonomy-supportive strategies, their use of controlling coaching practices may have decreased through the process from pretest to posttest. However, based on sensitivity analyses, results from pretest to follow-up are more ambiguous. That is, when analyzing complete cases (i.e., coaches who did not drop out on T3) this significant interaction effect from pretest to posttest seemed to be sustained upon follow-up. However, analysis of data including imputed values of coaches whose data was missing at follow-up did not show such an interaction effect. Although significant short-term effects were found from pretest to posttest, this inconsistency may suggest caution towards the long-term effects on self-reported coach control from pretest to follow-up.

In contrast to findings for coaches' autonomy support and control, coaches in the intervention condition did not report changes in structure and chaos compared to coaches in the control group. However, the more long-term effects of the intervention for coach-reported structure differed, with coaches in the intervention group reporting an increase from pretest to follow-up. Part of the structuring strategies that were addressed during the training, particularly those that are related to the guidance of athletes, could be implemented in any training (e.g., expressing confidence in athletes' capabilities, offering help, providing 
informational feedback). As these strategies are more related to sport-specific coaching, they may be more self-evident and already applied by coaches in their daily practice. Yet, other strategies, especially those related to a clarifying approach (e.g., clarifying rules, guidelines and expectations, Delrue et al., 2018), are more typically implemented in the beginning of the season. Since most of the coaches passed from the end of one season to the start of another season between posttest and follow-up, this may explain why intervention effects on structure were clearer at follow-up. That is, coaches may think their athletes to benefit more from structure in the beginning of a season because of the new and unstructured environment in which their athletes are looking for guidance, orientation, and support. Results of multilevel modelling on coaches' self-reported need-supportive and need-thwarting coaching behavior seem to endorse this rationale, as a significant interaction effect was found on coaches' selfreported structure from posttest to follow-up.

\section{Athlete reports}

Similar to previous intervention work (e.g., Cheon et al., 2015, Aelterman et al., 2014) we moved beyond coach reports and tested effects on athletes' perceptions of their coaches (de)motivating coaching style. As hypothesized (i.e., Hypothesis 2) and congruent with previous studies within the sport context (Cheon et al., 2015), athletes in the intervention group found their coach to increasingly adopt an autonomy-supportive coaching style. A parallel decrease in controlling coaching behavior was not reported by athletes in the intervention group. Although this specific finding is in line with research by Langan et al. (2015), Cheon et al. (2015) reported that their training program impact upon Paralympic athletes' perceived controlling coaching behavior as well. Possibly, the high-stakes competitive environment of the Paralympics may account for this effect, as participants in the control group reported an increase in controlling behavior towards the start of the competition. 
Whereas coaches in the intervention condition did not report increasingly adopting a structuring style from pretest to posttest, athletes reported that coaches had made substantial changes in structuring coach behavior. Further, while athletes in the control group reported their coaches to become more chaotic from pre- to posttest, this was not the case for athletes in the intervention group. Possibly coaches become more permissive towards the end of a season, thereby leaving their athletes more to their own devices. That is, coaches can be more (emotionally) exhausted, less motivated or lower in energy (Bentzen, M., Lemyre, P.N., Kenttä, G., 2015; Raedeke, 2004). As a result, coaches may become less demanding towards their athletes and therefore less firmly monitor guidelines and expectations (Mageau \& Vallerand, 2003). As a result, coaches may become less demanding towards their athletes and therefore less firmly monitor guidelines and expectations (Mageau \& Vallerand, 2003). Besides, the end of a sport season may correspond with the 'adjourning' phase in Tuckman's theory of stages of group development (Tuckman, 1965; Tuckman \& Jensen, 1977; Tekleab, Quigley, \& Tesluk, 2009). The adjourning phase follows from task completion and reflects the final stage of group development in which a team reaches termination. Within this stage, guiding of the leader is limited and individuals of the group are characterized by increased independency and disengagement from the leader (Tuckman \& Jensen, 1977). In this regard, the timing of the measurements may partially account for the results. However, the intervention program may have functioned as a buffer against an increase in chaotic coaching towards the end of the season.

In conclusion, while coaches might feel that they invested considerably in improving their autonomy support and less in improving structure, they seem to have adopted an increasingly structuring style as well in the eyes of their athletes. Possibly, the discrepancy in coach and athlete reports of intervention effect on structure and chaos may be due to the fact that coaches overestimate their amount of provided structure at pretest, thereby obscuring 
possible intervention effects in reality. In fact, many coaches dislike chaos and social response tendencies may partially account for their elevated structure and reduced chaos scores (Delrue et al., 2018). Because athletes may be less prone to such social desirable response tendencies, they may be a more reliable source of information to gain insight in the real intervention effects.

Besides changes in coaches' need support, our aim was to examine whether changes would be found in athletes' engagement and motivation. In line with previous research (Amorose \& Anderson-Butcher, 2007; Mageau \& Vallerand, 2003) and our expectations, athletes in the intervention group reported an increase in their autonomous motivation from pretest to posttest compared to athletes in the control group, whereas no changes were reported regarding their controlled motivation. Recent research revealed that need-supportive coaching clearly differs from the absence of need-thwarting coaching behavior and vice versa (e.g., Bartholomew, 2010; Haerens et al., 2015). That is, changes in need-supportive coaching behavior do not necessarily ensure changes in need-thwarting behavior as well. As this needthwarting coaching behavior, and a controlling style in particular, has been shown to be a unique predictor of controlled motivation (e.g., Haerens et al., 2015; Pelletier et al., 2001), changes in need-supportive coaching were not expected to induce changes in controlled motivation. Given that our program aimed to foster coaches' autonomy-supportive and structuring behavior instead of learning coaches how to reduce their need-thwarting behavior and the lack of significant changes in athletes' perceived controlling coaching, it is conceivable that our program did not automatically lead to a decrease in controlled motivation.

Although more autonomous motivation may yield a broad range of desirable outcomes, it is not easy, even difficult, for coaches to infer athletes' autonomous motivation as this concerns an intrapersonal experience to which coaches do not have easily access. Therefore, 
increasing attention has been paid to the concept of engagement, which is considered a more overt expression of one's motivation (Lee \& Reeve, 2012). Engagement can be considered as an important outcome for coaches as it denotes their athletes' positive, high-quality, and active involvement in a learning task or activity (Skinner, Kindermann, Connell \& Wellborn, 2009; Fredricks, Blumenfeld, \& Paris, 2004). Therefore, in addition to quality of motivation, we also investigated whether the intervention program impacted on athletes' engagement. For youth athletes to display engagement, they need to find themselves in an environment which allows and encourages them to be actively involved at their own pace of development, and display trust in their capacity to do so (Curran, Hill \& Niemiec, 2013). Such an environment is central to a need-supportive coaching style. That is, by capitalizing on athletes' inner motivational resources and allowing them to voice their questions and difficulties, interests and preferences, youth athletes are likely to be more persistent and attentive (behavioral engagement), to feel less stressed and anxious (emotional engagement), to use different and more sophisticated problem-solving strategies (cognitive engagement) and to take more initiative to express their thoughts, feelings or opinions (agentic engagement). In line with our expectations, athletes' engagement increased.

\section{Type of Sports}

Previous SDT-based interventional research within the sport context focused on either individual (e.g., Cheon, Reeve, Lee \& Lee, 2015), or team sport settings (e.g., Langan et al., 2015). Because this study tested the trainability of a need-supportive coaching style within different team sports and individual sports, we were able to explore the moderating role of sport type. Although athletes in the intervention group reported an increase regarding their coaches' autonomy support and structure in general, a breakdown by type of sports indicated that these effects were largely driven by the significant effects among athletes of individual sports. 
Several explanations are possible for these findings. First, besides the fact that this diversity may result from a prevailing coaching culture within different types of sports, the complexity of team sport coaching may elicit different coaching behavior and require additional coaching skills (Cushion, Ford, \& Williams, 2012; van de Pol, Kavussanu, \& Kompier, 2015). That is, whereas team sport coaches are often facing a lack of time or opportunities, in individual sports, a more one-on-one relationship can be expected between coaches and athletes. Such a one-on-one relationship may not only make it easier for athletes to notice changes in their coaches' behaviors but also promote coaches' behavior to be more individually-oriented and hence makes it more straightforward and feasible to implement autonomy-supportive (e.g., promote dialogue, consult athletes' opinions, give rationale, welcome negative affect) and structuring behavior (clarify expectations, provide individual feedback, display confidence, provide help) compared to a team sport setting (van de Pol, Kavussanu, \& Kompier, 2015). For example, Chelladurai and Turner (2006) and Vroom and Jago (2007) emphasize the situation and context being key to understand decision making in teams (Cushion, Ford, \& Williams, 2012). That is, a number of relevant contextual and situational attributes (e.g., relative information, time pressure, problem complexity, required decision quality, group integration) need to be considered in the decision making process in team sport settings (Chelladurai \& Turner, 2006), and these factors may challenge the coach to act in a need-supportive way. Hence, the intervention program may not have dealt properly with these situational and contextual factors, which determine a different need-supportive approach within team and individual sport types.

Regarding athlete outcomes, engagement was moderated by sport type. More specifically, whereas individual and team sport athletes in the control group reported a rather status quo, a significant increase was found for individual sport athletes in the intervention group. However, it should be noted that also team sport athletes in the intervention group reported a 
trend towards a significant increase in their engagement. In contrast, no moderation by sport type was found for athletes' autonomous motivation, suggesting that the positive changes which were found for athletes' motivation appeared in both individual and team sport athletes. In other words, although team sport athletes did not notice substantial changes in perceived coaching style (i.e., autonomy support and structure), they do seem to benefit from the fact that their coach followed the training program. Maybe, some other coaching behaviors, which are not explicitly categorized as autonomy-supportive or structuring coach behavior, were picked up by coaches during the training program and hence accounted for and contributed to changes in athletes' autonomous motivation. Alternatively, team sports coaches may have particularly focused on the application of one specific autonomy-supportive or structuring strategy. For example, towards the end of the season, coaches may focus more on fun elements (i.e., nurture inner motivational resources) within their coaching practice to counter a decline in athletes' motivation. The intense application of this strategy may have been experienced by athletes, thereby affecting their autonomous motivation. However, focusing on one specific strategy may have diluted the effect on perceived autonomy support and structure in general, as athletes were asked to report on a more comprehensive autonomysupportive and structuring coaching style, by assessing a variety of different strategies throughout several situations.

\section{Limitations and Future Research}

Despite its strengths, this study also has its limitations, leading to some suggestions for future research. First, the timing of measurement points in this study may be considered as a limitation. We opted to not start our intervention program at the beginning of a season to ensure that athletes could make an accurate evaluation of their coaches' behavior. As a drawback, it may have been harder for coaches to make progress regarding their provision of structure as many expectations, agreements, guidelines and goals are being discussed at the 
beginning of a season, and it may be hard for coaches to come back on their approaches when the season is already ongoing. Moreover, because the follow-up measurement took place during the next season, we were unable to contact athletes for a third measurement and a substantial percentage of the coaches dropped out of the study, precluding us from examining follow-up effects among athletes. Future intervention studies may start earlier in the season such that coaches and athletes could be followed multiple times over a single season. In the best case, coaches would be followed over multiple seasons as to examine whether they would continue engaging in need-supportive practices even when coaching a new group of athletes.

Second, coaches of both intervention and control group voluntarily accepted to take part in this study, resulting in a selective sample of coaches who were interested in the topic of motivational coaching and therefore were perhaps more eager to implement need-supportive strategies in their coaching practice. Future research within less selective samples of coaches may be needed to examine whether the current findings can be generalized.

Third, and in line with previous limitation, another limitation concerns the limited implementation of blinding procedures within the study. The reliance on coach self-reports may have caused subject bias as coaches in the experimental group may have developed certain expectations regarding the effectiveness of the intervention program, thereby leading to an overestimation of its effectiveness. A placebo intervention offered to coaches in the control group would have been an example of effective blinding, as coaches in both groups (i.e., intervention and control) would have undergone an intervention, thereby eliciting biased responding among both of them. To overcome this issue, athlete reports were collected as well. Also, athletes were blinded as researchers did not inform them on the aim of the study neither on whether their coaches were following an intervention program. Moreover, coaches were explicitly instructed to stay silent about their participation in a coach intervention 
program vis-à-vis their athletes. Besides avoiding disclosure of the study hypotheses towards the athletes we avoided contact between participants (i.e., both coaches and athletes) in each conditions by allocating coaches or teams from the same club to the same condition. In sum, blinding, and especially double-blinding (i.e., both blinding on the assessor and participant side) can be challenging for researchers setting up an intervention study. Nevertheless, while it has become one of the key features of clinical trials (e.g., Bang \& Davis, 2004), blinding may be more rigorously been attended to in future intervention research within the domain of sports coaching as well.

Fourth, it would be interesting for future research to address relatedness support in the intervention program, and to consequently include it as a separate outcome. This would also allow to investigate whether intervention effects can be enhanced when all three needs are addressed, or whether addressing one need has a clearly stronger effect compared to another. In line with this, it would be interesting to also include measures of athletes' amotivation. Given that the primary focus of the intervention was to strengthen coaches' need-supportive coaching style rather than to reduce the reliance on a need-thwarting coaching style, the inclusion of amotivation was deemed less useful. Nevertheless, it may have been worthwhile to measure amotivation, especially at Time 2 (i.e. the end of the season), as amotivation has been found to be a robust predictor of drop-out (Pelletier et al., 2001).

Finally, as current research involved youth athletes, the question may arise if the same effects could be generalized to samples of adult or elite athletes. On the one hand, coaches may make more frequent use of autonomy- supportive strategies in older or elite athletes as these athletes are more experienced, knowledgeable and skilled compared to younger athletes. On the other hand, given the many pressures coaches in elite sport settings face, they may adopt a more controlling approach. Because of the high-stakes, competitive environment in which they need to perform, elite coaches may feel accountable and responsible for results 
and therefore be less open to change their behavior and stick to those behaviors where the coach him-/herself is in charge (e.g., control) (Cushion, Ford \& Williams, 2012, Ntoumanis \& Mallet, 2014). However, to answer these questions, future research is needed to study needsupportive coaching in a situation-specific way within an elite sport setting.

\section{Conclusion}

Taken together, the results of this study are hopeful as findings showed the intervention program to be successful in training coaches to adopt a need-supportive coaching style. That is, after the coaches completed the intervention, both coaches and their athletes reported significant positive changes regarding coaches' autonomy-supportive and structuring coaching behavior, except for team sport athletes. Moreover, athletes indicated an increase in their autonomous motivation and engagement. As these outcomes are known to be essential in order to keep their athletes engaged and motivated towards sustainable sport participation (e.g., Gillet et al., 2012), it is worthwhile for coaches to invest in need-supportive coaching. 


\section{References}

Aelterman, N., De Muynck, G., Haerens, L., Vande Broek, G. \& Vansteenkiste, M. (2017). Motiverend coachen in de sport. Leuven: Acco.

Aelterman, N., Vansteenkiste, M., Van den Berghe, L., De Meyer, J., \& Haerens, L. (2014). Fostering a need-supportive teaching style: Intervention effects on physical education teachers' beliefs and teaching behaviors. Journal of Sport \& Exercise Psychology, 36, 595-609.

Aelterman, N., Vansteenkiste, M., Van Keer, H., De Meyer, J., Van den Berghe, L., \& Haerens, L. (2013). Development and evaluation of a training on need-supportive teaching in physical education: Qualitative and quantitative findings. Teaching and Teacher Education, 29, 64-75.

Amorose, A.J., \& Anderson-Butcher, D. (2007). Autonomy-supportive coaching and selfdetermined motivation in high school and college athletes: A test of self-determination theory. Psychology of Sport and Exercise, 8, 654-670.

Assor, A., Vansteenkiste M., \& Kaplan, A. (2009). Identified versus introjected-approach and introjected-avoidance motivations in school and in sports: The limited benefits of selfworth strivings. Journal of Educational Psychology, 101, 482-497.

Azur, M. J., Stuart, E. A., Frangakis, C., \& Leaf, P. J. (2011). Multiple imputation by chained equations: what is it and how does it work? International Journal of Methods in Psychiatric Research, 20, 40-49.

Balaguer, I., Gonzalez, L., Fabra, P., Castillo, I., Merce, J., \& Duda, J. L. (2012). Coaches' interpersonal style, basic psychological needs and the well- and ill-being of young soccer players: A longitudinal analysis. Journal of Sports Sciences, 30, 1619-1629.

Bang, H., Ni, L., \& Davis, C. E. (2004). Assessment of blinding in clinical trials. Controlled Clinical Trials, 25, 143-156. 
Bartholomew, K. J., Ntoumanis, N., \& Thøgersen-Ntoumani, C. (2010). The controlling interpersonal style in a coaching context: development and initial validation of a psychometric scale. Journal of Sport \& Exercise Psychology, 32, 193-216.

Bentzen, M., Lemyre, P.N., Kenttä, G. (2015). Changes in motivation and burnout indices in high-performance coaches over the course of a competitive season. Journal of Applied Sport Psychology, 28, 28-48.

Chelladurai, P., and Turner, B. (2006). Styles of decision making in coaching. In Williams, J. (Ed.), Applied Sport Psychology: Personal Growth to Peak Performance. Boston: McGraw-Hill.

Cheon, S. H., \& Reeve, J. (2013). Do the benefits from autonomy-supportive PE teachertraining programs endure? A one-year follow-up investigation. Psychology of Sport and Exercise, 14, 508-518.

Cheon, S.H., Reeve, J., Lee, J., \& Lee, Y. (2015). Giving and receiving autonomy support in a high-stakes sport context: A field-based experiment during the 2012 London Paralympic Games. Psychology of Sport and Exercise, 19, 59-69.

Conroy, D. E., \& Coatsworth, J. D. (2007). Assessing autonomy-supportive coaching strategies in youth sport. Psychology of Sport \& Exercise, 8, 671-684.

Crane, J., \& Temple, V. (2015). A Systematic Review of Dropout from Organized Sport among Children and Youth. European Physical Education Review, 21, 114-131.

Curran, T., Hill, A. P., Hall, H.K., \& Jowett, G. E. (2014). Perceived coach behaviours and athletes' engagement and disaffection in youth sport: The mediating role of the psychological needs. International Journal of Sport Psychology, 45, 559-580.

Curran T., Hill A. P., Niemiec C. P. (2013). A conditional process model of children's behavioral engagement and behavioral disaffection in sport based on self-determination theory. Journal of Sport and Exercise Psychology, 35, 30-43. 
Cushion, C., Ford, P. R., \& Williams, A. M. (2012). Coach behaviours and practice structures in youth soccer: Implications for talent development. Journal of Sports Sciences, 30, $1631-1641$

Deci, E. L., \& Ryan, R. M. (2000). The "what" and "why" of goal pursuits: Human needs and the self-determination of behavior. Psychological Inquiry, 11, 227-268.

Delrue, J., Haerens, L. Mouratidis, A., Gevaert, K., Vande Broek, G., \& Vansteenkiste, M. (2017). A game-to-game investigation in the relation between need-supportive and needthwarting coaching and moral behavior in soccer. Psychology of Sport and Exercise, 31, $1-10$.

Delrue, J.*, Reynders, B.*, Aelterman, N., De Backer, M., Decroos, S., De Muynck, G., Fontaine, J., Fransen, K., Haerens, L., Van Puyenbroeck, S., Vande Broek, G., \& Vansteenkiste, M. (2019). Adopting a Helicopter-perspective towards Motivating and Demotivating Coaching Behavior: A Circumplex Approach. Psychology of Sport and Exercise, 40, 110-126.

De Muynck, G., Vansteenkiste, M., Delrue, J., Aelterman, N., Haerens, L., \& Soenens, B. (2017). The effects of feedback valence and style on need satisfaction, self-talk, and perseverance among tennis players: An experimental study. Journal of Sport and Exercise Psychology, 39, 67-80.

Fredricks, J. A., Blumenfeld, P. C., \& Paris, A. H. (2004). School engagement Potential of the concept, state of the evidence. Review of Educational Research, 74, 59-109.

Gillet, N., Vallerand, R. J., Amoura, S., Baldes, B. (2010). Influence of coaches' autonomy support on athletes' motivation and sport performance: A test of the hierarchical model of intrinsic and extrinsic motivation. Psychology of Sport and Exercise, 11, 155-161. 
Gillet, N., Berjot, S., Vallerand, R. J., \& Amoura, S. (2012). The role of autonomy support and motivation in the prediction of interest and dropout intentions in sport and education settings. Basic and Applied Social Psychology, 34, 278-286.

Haerens, L., Aelterman, N., Vansteenkiste, M., Soenens, B., \& Van Petegem, S. (2015). Do perceived autonomy-supportive and controlling teaching relate to physical education students' motivational experiences through unique pathways? Distinguishing between the bright and dark side of motivation. Psychology of Sport and Exercise, 16, 26-36.

Haerens, L., Vansteenkiste, M., De Meester, A., Delrue, J., Tallir, I., Vande Broek, G., Goris, W., \& Aelterman, N. (2018). Different combinations of perceived autonomy support and control: identifying the most optimal motivating style. Physical Education and Sport Pedagogy, 23, 16-36.

Hox, J. (2002). Multilevel Analysis: Techniques and Applications. Mahwah, NJ: Lawrence Erlbaum.

Langan, E., Blake, C., \& Lonsdale, C. (2013). Systematic review of the effectiveness of interpersonal coach education interventions on athlete outcomes. Psychology of Sport and Exercise, 14, 37-49.

Langan, E., Toner, J., Blake, C., \& Lonsdale, C. (2015). Testing the effects of a selfdetermination theory-based intervention with youth Gaelic football coaches on athlete motivation and burnout. Sport Psychologist, 29, 293-301.

Larsen, T., Van Hoye, A., Tjomsland, H.E., Holsen, I., Wold, B., Huezé, J., Samdal, O., \& Sarrazin, P. (2015). Creating a supportive environment among youth football players: A qualitative study of French and Norwegian youth grassroots football coaches. Health Education, 115, 570-586.

Lee, W., \& Reeve, J. (2012). Teachers' estimates of their students' motivation and engagement: being in synch with students. Educational Psychology, 32, 727-747. 
Lonsdale, C., Hodge, K., \& Rose, E. A. (2008). The behavioral regulation in sport questionnaire (BRSQ): instrument development and initial validity evidence. Journal of Sport \& Exercise Psychology, 30, 323-355.

Lyle, J. (2002). Sports Coaching Concepts: A. Framework for Coaches'Behaviour. London: Routledge.

Maas, C.J.M., \& Hox, J.J. (2005). Sufficient sample sizes for multilevel modeling. Methodology, 1, 86-92.

Mageau, G. A., \& Vallerand, R. J. (2003). The coach-athlete relationship: A motivational model. Journal of Sports Sciences, 21, 883-904.

Ntoumanis, N., \& Mallet, C. (2014). Motivation in sport: A self-determination theory perspective. In Papaioannou, A. \& Hackfort, D., Routledge Companion to Sport and Exercise Psychology: Global perspectives and fundamental concepts (pp. 67-82). London: Routledge.

Pelletier, L. G., Fortier, M. S., Vallerand, R. J., \& Brière, N. M. (2001). Associations among perceived autonomy support, forms of self-regulation, and persistence: A prospective study. Motivation and Emotion, 25, 279-306.

Podlog, L., Gustafsson, H., Skoog, T., Gao, Z., Maria, W., Werner, S. \& Alricsson, M. (2015). Need satisfaction, motivation, and engagement among high Performance youth athletes: A multiple mediation analysis. International Journal of Sport and Exercise Psychology, 13, 415-433.

Raedeke, T. D. (2004). Coach commitment and burnout: A one-year follow-up. Journal of Applied Sport Psychology, 16, 333-349.

Reeve, J. (2009). Why Teachers Adopt a Controlling Motivating Style Toward Students and How They Can Become More Autonomy Supportive. Educational Psychologist, 44, 159175. 
Reeve, J. (2013). How students create motivationally supportive learning environments for themselves: The concept of agentic engagement. Journal of Educational Psychology, 105, 579-595.

Reeve, J., \& Tseng, C.-M. (2011). Agency as a fourth aspect of students' engagement during learning activities. Contemporary Educational Psychology, 36, 257-267.

Richardson, J. (2011). Eta squared and partial eta squared as measurements of effect size in educational research. Educational Research Review, 6, 135-147.

Ryan, R., \& Deci, E. (2000). Self-Determination Theory and the Facilitation of Intrinsic Motivation, Social Development, and Well-Being. American Psychologist, 55, 68-78.

Ryan, R., \& Deci, E. (2017). Self-Determination Theory: Basic psychological needs in motivation, development, and wellness. New York: Guilford Press.

Schafer, J. L. (1999). Multiple imputation: a primer. Statistical Methods in Medical Research, $8,3-15$.

Skinner E., Kindermann, T., \& Furrer, C. (2009). A motivational perspective on engagement and disaffection: Conceptualization and assessment of children's behavioral and emotional participation in academic activities in the classroom. Educational and Psychological Measurement, 69, 493-525.

Soenens, B. \& Vansteenkiste, M. (2010). A theoretical upgrade of the concept of parental psychological control: Proposing new insights on the basis of Self-Determination Theory. Developmental Review, 30, 74-99.

Sparks, C., Dimmock, J., Whipp, P., Lonsdale, C., \& Jackson, B. (2015). Getting connected: High school physical education teacher behaviors that facilitate students' relatedness support perceptions. Sport, Exercise, and Performance Psychology, 4, 219-236. 
Stebbings, J., Taylor, I. M., Spray, C. M., \& Ntoumanis, N. (2012). Antecedents of perceived coach interpersonal behaviors: The coaching environment and coach psychological welland ill-being. Journal of Sport and Exercise Psychology, 34, 481-502.

Su, Y. L., \& Reeve, J. (2011). A meta-analysis of the effectiveness of intervention programs designed to support autonomy. Educational Psychology Review, 23, 159-188.

Tekleab, A.G., Quigley, N.R., \& Tesluk, P.E. (2009). A longitudinal study of team conflict, conflict management, cohesion, and team effectiveness. Group and Organization Management, 34, 170-205.

Tuckman, B. W. \& M. C. Jensen. (1977). Stages of Small Group Development Revisited. Group and Organizational Studies, 2, 419-427.

van de Pol, P., Kavussanu, M., \& Kompier, M. (2015). Autonomy support and motivational responses across training and competition in individual and team sports. Journal of Applied Social Psychology, 45, 697-710.

Vansteenkiste, M., Sierens, E., Soenens, B., Luyckx, K., \& Lens, W. (2009). Motivational profiles from a self-determination perspective: The quality of motivation matters. Journal of Educational Psychology, 101, 671-688.

Vansteenkiste, M., and B. Soenens. (2015). Vitamines voor groei: Ontwikkeling voeden vanuit de Zelf-Determinatie Theorie. Leuven: Acco.

Vlaamse Trainersschool. (2018). Visienota 2025 Vlaamse Trainersschool. Brussel: Vlaamse Trainersschool.

Vroom, V. H., \& Jago, A. G. (2007). The role of the situation in leadership. American Psychologist, 62, 17-24.

Wolters, C. A. (2004). Advancing achievement goal theory: Using goal structures and goal orientations to predict students' motivation, cognition, and achievement. Journal of Educational Psychology, 96, 236-250. 


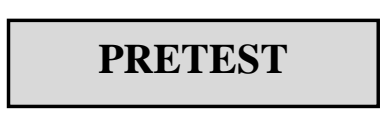

\section{INTERVENTION PROGRAM}

Baseline

\section{Coaches}

Self-reported need-

supportive and need-

thwarting coaching

Athletes

Perceived autonomy

support, structure,

control \& chaos

Self-reported

autonomous \&

controlled motivation

Self- reported

engagement

23

24

25 Figure 1. Timeline of the study protocol. IS = Initiation Session; WS = Workshop.

\section{FOLLOW-UP}

4 months later

\section{3 weeks later}

\section{Coaches}

Self-reported need-

supportive and need-

thwarting coaching

Athletes

Perceived autonomy

support, structure,

control \& chaos

Self-reported

autonomous \&

controlled motivation

Self- reported

engagement
Coaches

Self-reported need-

supportive and need-

thwarting coaching 
Allocated to intervention group ( $n=23$ coaches, 177 athletes)

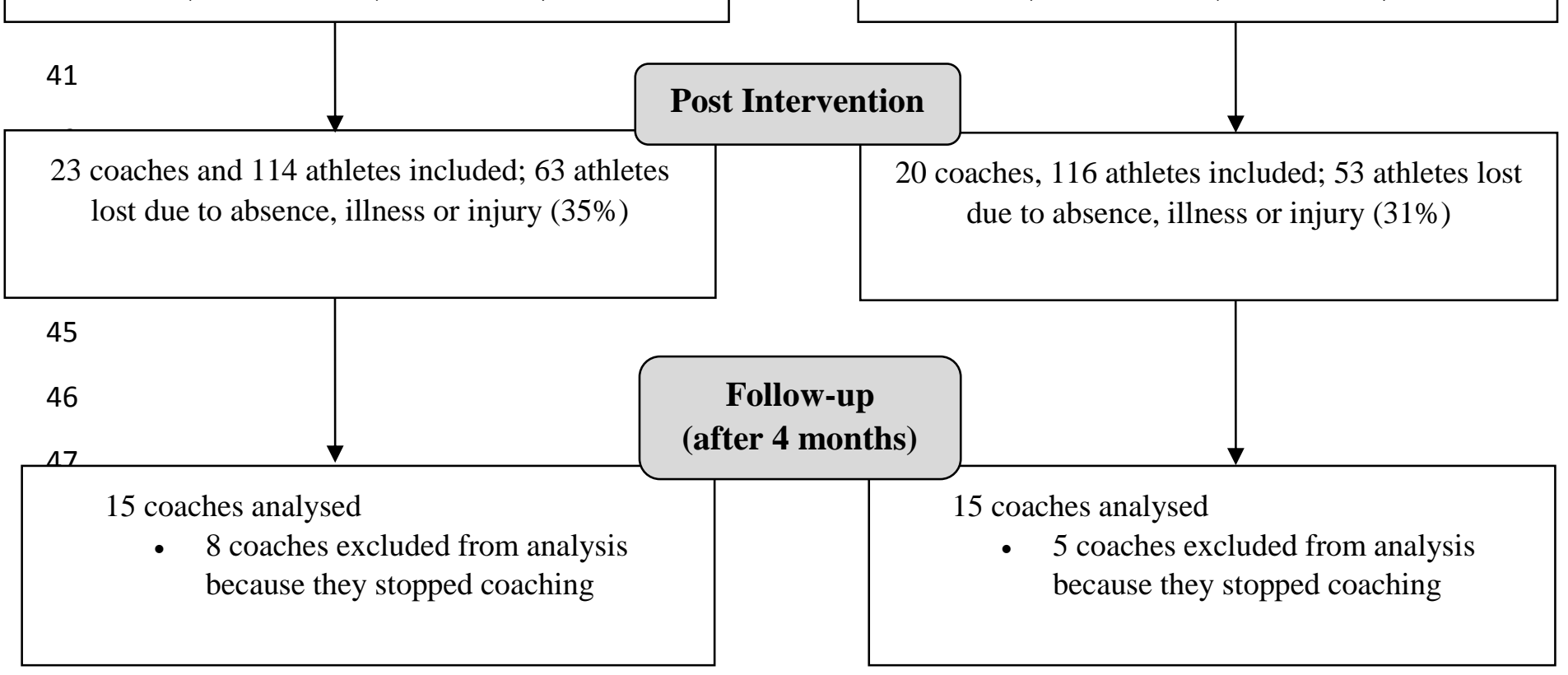

51 Figure 2. Intervention flow chart. 
52 Table 1. Intervention effects from pretest to posttest for coaches' self-reported autonomy support, structure, control and chaos, within full sample 53 of coaches $(N=43)$.

\begin{tabular}{|c|c|c|c|c|c|c|c|c|c|c|c|}
\hline & \multicolumn{3}{|c|}{ Descriptives } & \multicolumn{6}{|c|}{ Fixed Effects } & \multicolumn{2}{|c|}{ Random Effects } \\
\hline & \multirow[t]{2}{*}{$\begin{array}{l}\text { Pretest } \\
M(S D)\end{array}$} & \multirow[t]{2}{*}{$\begin{array}{r}\text { Posttest } \\
M(S D)\end{array}$} & \multirow[t]{2}{*}{$\Delta$} & \multicolumn{2}{|c|}{ Time } & \multicolumn{2}{|c|}{ Condition } & \multicolumn{2}{|c|}{$\begin{array}{c}\text { Time } \mathrm{x} \\
\text { Condition }\end{array}$} & \multirow[t]{2}{*}{ Residual } & \multirow[t]{2}{*}{$\begin{array}{c}\text { Level } 2 \\
\text { intercept }\end{array}$} \\
\hline & & & & $\beta$ & $S E$ & $\beta$ & $S E$ & $\beta$ & $S E$ & & \\
\hline \multicolumn{12}{|l|}{ Autonomy support } \\
\hline Control group & $5.19 \pm .52$ & $5.22 \pm .45$ & .03 & & & & & & & & \\
\hline Intervention group & $5.08 \pm .66$ & $5.59 \pm .70$ & .51 & & & & & & & & \\
\hline Total & $5.19 \pm .60$ & $5.42 \pm .62$ & .23 & 0.03 & .27 & $-0.61^{*}$ & .30 & $0.48^{* *}$ & .18 & 0.17 & 0.17 \\
\hline \multicolumn{12}{|l|}{ Structure } \\
\hline Control group & $5.71 \pm .49$ & $5.85 \pm .46$ & .14 & & & & & & & & \\
\hline Intervention group & $5.52 \pm .71$ & $5.63 \pm .59$ & .11 & & & & & & & & \\
\hline Total & $5.61 \pm .61$ & $5.74 \pm .56$ & .13 & 0.15 & .19 & -0.24 & .25 & -0.01 & .12 & 0.09 & 0.26 \\
\hline \multicolumn{12}{|l|}{ Control } \\
\hline Control group & $3.02 \pm .60$ & $3.23 \pm .56$ & .21 & & & & & & & & \\
\hline Intervention group & $3.08 \pm .67$ & $2.60 \pm .75$ & -.48 & & & & & & & & \\
\hline Total & $3.05 \pm .63$ & $2.89 \pm .72$ & -.16 & 0.20 & .12 & 0.74 & .29 & $-0.69^{* * *}$ & .17 & 0.14 & 0.26 \\
\hline \multicolumn{12}{|l|}{ Chaos } \\
\hline Control group & $2.27 \pm .58$ & $2.43 \pm .55$ & .16 & & & & & & & & \\
\hline Intervention group & $2.23 \pm .53$ & $2.28 \pm .62$ & .05 & & & & & & & & \\
\hline Total & $2.25 \pm .50$ & $2.35 \pm .58$ & .10 & 0.16 & .11 & 0.15 & .27 & -0.15 & .16 & 0.13 & 0.14 \\
\hline
\end{tabular}


Table 2. Intervention effects from pretest to follow-up for coaches' self-reported autonomy support, structure, control and chaos, within sample

57 that filled out pre-test and follow-up $(N=30)$.

\begin{tabular}{|c|c|c|c|c|c|c|c|c|c|c|c|}
\hline & \multicolumn{3}{|c|}{ Descriptives } & \multicolumn{6}{|c|}{ Fixed Effects } & \multicolumn{2}{|c|}{ Random Effects } \\
\hline & \multirow[t]{2}{*}{$\begin{array}{l}\text { Pretest } \\
M(S D)\end{array}$} & \multirow[t]{2}{*}{$\begin{array}{l}\text { Follow-up } \\
M(S D)\end{array}$} & \multirow[t]{2}{*}{$\Delta$} & \multicolumn{2}{|c|}{ Time } & \multicolumn{2}{|c|}{ Condition } & \multicolumn{2}{|c|}{$\begin{array}{c}\text { Time } \mathrm{x} \\
\text { Condition }\end{array}$} & \multirow[t]{2}{*}{ Residual } & \multirow[t]{2}{*}{$\begin{array}{c}\text { Level } 2 \\
\text { intercept }\end{array}$} \\
\hline & & & & $\beta$ & $S E$ & $\beta$ & $S E$ & $\beta$ & $S E$ & & \\
\hline \multicolumn{12}{|l|}{ Autonomy support } \\
\hline Control group & $5.14 \pm .53$ & $5.33 \pm .53$ & .19 & & & & & & & & \\
\hline Intervention group & $4.93 \pm .81$ & $5.44 \pm .95$ & .51 & & & & & & & & \\
\hline Total & $5.04 \pm .68$ & $5.39 \pm .76$ & .14 & 0.11 & .06 & -0.24 & .22 & 0.11 & .08 & 0.11 & 0.27 \\
\hline \multicolumn{12}{|l|}{ Structure } \\
\hline Control group & $5.76 \pm .47$ & $5.75 \pm .54$ & -.01 & & & & & & & & \\
\hline Intervention group & $5.31 \pm .71$ & $5.79 \pm .75$ & .48 & & & & & & & & \\
\hline Total & $5.54 \pm .63$ & $5.77 \pm .64$ & .23 & -0.01 & .04 & $-0.48^{*}$ & .23 & $0.23^{* * *}$ & .07 & 0.07 & 0.34 \\
\hline \multicolumn{12}{|l|}{ Control } \\
\hline Control group & $2.97 \pm .56$ & $3.37 \pm .81$ & .40 & & & & & & & & \\
\hline Intervention group & $3.15 \pm .67$ & $2.84 \pm .73$ & -.31 & & & & & & & & \\
\hline Total & $3.06 \pm .62$ & $3.10 \pm .80$ & .04 & $0.19^{*}$ & 0.09 & 0.38 & .28 & $-0.33^{* *}$ & .13 & 0.26 & .20 \\
\hline \multicolumn{12}{|l|}{ Chaos } \\
\hline Control group & $2.23 \pm .50$ & $2.21 \pm .65$ & -.03 & & & & & & & & \\
\hline Intervention group & $2.42 \pm .52$ & $2.18 \pm .48$ & -.24 & & & & & & & & \\
\hline Total & $2.33 \pm .51$ & $2.20 \pm .56$ & -.13 & -0.03 & 0.07 & 0.03 & .22 & -0.03 & .10 & 0.17 & 0.08 \\
\hline
\end{tabular}

Note. $* p<.05, * * p<.01 * * p<.001$ 
Table 3. Intervention effects from posttest to follow-up for coaches' self-reported autonomy support, structure, control and chaos, within sample

61 that filled out posttest and follow-up $(N=30)$.

\begin{tabular}{|c|c|c|c|c|c|c|c|c|c|c|c|}
\hline & \multicolumn{3}{|c|}{ Descriptives } & \multicolumn{6}{|c|}{ Fixed Effects } & \multicolumn{2}{|c|}{ Random Effects } \\
\hline & \multirow[t]{2}{*}{$\begin{array}{c}\text { Posttest } \\
M(S D)\end{array}$} & \multirow[t]{2}{*}{$\begin{array}{l}\text { Follow-up } \\
M(S D)\end{array}$} & \multirow[t]{2}{*}{$\Delta$} & \multicolumn{2}{|c|}{ Time } & \multicolumn{2}{|c|}{ Condition } & \multicolumn{2}{|c|}{$\begin{array}{c}\text { Time } \mathrm{x} \\
\text { Condition }\end{array}$} & \multirow[t]{2}{*}{ Residual } & \multirow[t]{2}{*}{$\begin{array}{l}\text { Level } 2 \\
\text { intercept }\end{array}$} \\
\hline & & & & $\beta$ & $S E$ & $\beta$ & $S E$ & $\beta$ & $S E$ & & \\
\hline \multicolumn{12}{|l|}{ Autonomy support } \\
\hline Control group & $5.22 \pm .51$ & $5.33 \pm .53$ & .11 & & & & & & & & \\
\hline Intervention group & $5.32 \pm .67$ & $5.44 \pm .95$ & .12 & & & & & & & & \\
\hline Total & $5.27 \pm .59$ & $5.39 \pm .76$ & .12 & 0.17 & .13 & 0.45 & .47 & -0.06 & .18 & 0.13 & 0.25 \\
\hline \multicolumn{12}{|l|}{ Structure } \\
\hline Control group & $5.91 \pm .50$ & $5.75 \pm .54$ & -.16 & & & & & & & & \\
\hline Intervention group & $5.43 \pm .60$ & $5.79 \pm .75$ & .36 & & & & & & & & \\
\hline Total & $5.67 \pm .60$ & $5.77 \pm .64$ & .10 & -0.14 & .11 & $-1.15^{* *}$ & .42 & $0.45^{\text {*** }}$ & .16 & 0.10 & 0.23 \\
\hline \multicolumn{12}{|l|}{ Control } \\
\hline Control group & $3.24 \pm .64$ & $3.37 \pm .81$ & .13 & & & & & & & & \\
\hline Intervention group & $2.62 \pm .76$ & $2.84 \pm .73$ & .22 & & & & & & & & \\
\hline Total & $2.93 \pm .76$ & $3.10 \pm .80$ & .17 & 0.14 & .17 & -0.81 & .59 & 0.08 & .23 & 0.23 & 0.23 \\
\hline \multicolumn{12}{|l|}{ Chaos } \\
\hline Control group & $2.44 \pm .57$ & $2.21 \pm .65$ & -.23 & & & & & & & & \\
\hline Intervention group & $2.32 \pm .66$ & $2.18 \pm .48$ & -.14 & & & & & & & & \\
\hline Total & $2.39 \pm .61$ & $2.20 \pm .56$ & -.19 & $-0.26^{* *}$ & .11 & -0.48 & .40 & 0.16 & .15 & 0.10 & 0.17 \\
\hline
\end{tabular}

Note. $* p<.05, * * p<.01 * * p<.001$ 
Table 4. Intervention effects from pretest to posttest for athletes' perceived need-supportive and need-thwarting behavior.

\begin{tabular}{|c|c|c|c|c|c|c|c|c|c|c|c|c|}
\hline & \multicolumn{3}{|c|}{ Descriptives } & \multicolumn{6}{|c|}{ Fixed Effects } & \multicolumn{3}{|c|}{ Random Effects } \\
\hline & \multirow[t]{2}{*}{$\begin{array}{l}\text { Pretest } \\
M(S D)\end{array}$} & \multirow[t]{2}{*}{$\begin{array}{l}\text { Posttest } \\
M(S D)\end{array}$} & \multirow[t]{2}{*}{$\Delta$} & \multicolumn{2}{|c|}{ Time } & \multicolumn{2}{|c|}{ Condition } & \multicolumn{2}{|c|}{$\begin{array}{c}\text { Time } \mathrm{x} \\
\text { Condition }\end{array}$} & \multirow[t]{2}{*}{ Residual } & \multirow[t]{2}{*}{$\begin{array}{c}\text { Level } 2 \\
\text { intercept }\end{array}$} & \multirow[t]{2}{*}{$\begin{array}{l}\text { Level } 3 \\
\text { intercept }\end{array}$} \\
\hline & & & & $\beta$ & $S E$ & $\beta$ & $S E$ & $\beta$ & $S E$ & & & \\
\hline \multicolumn{13}{|l|}{ Autonomy support } \\
\hline Control group & $4.56 \pm .92$ & $4.50 \pm .94$ & -.04 & & & & & & & & & \\
\hline Intervention group & $4.52 \pm .75$ & $4.76 \pm .81$ & .20 & & & & & & & & & \\
\hline Total & $4.54 \pm .84$ & $4.63 \pm .89$ & .07 & -0.04 & .06 & -0.20 & .22 & $0.27^{* *}$ & .09 & 0.27 & 0.24 & 0.27 \\
\hline \multicolumn{13}{|l|}{ Structure } \\
\hline Control group & $5.27 \pm .91$ & $5.09 \pm .99$ & -.18 & & & & & & & & & \\
\hline Intervention group & $5.06 \pm .78$ & $5.24 \pm .74$ & .18 & & & & & & & & & \\
\hline Total & $5.17 \pm .85$ & $5.16 \pm .89$ & -.01 & $-0.16^{*}$ & .07 & -0.39 & .24 & $0.32^{* * *}$ & .04 & 0.29 & 0.19 & 0.33 \\
\hline \multicolumn{13}{|l|}{ Control } \\
\hline Control group & $3.61 \pm .96$ & $3.82 \pm .89$ & .21 & & & & & & & & & \\
\hline Intervention group & $3.42 \pm .77$ & $3.47 \pm .83$ & .05 & & & & & & & & & \\
\hline Total & $3.51 \pm .88$ & $3.65 \pm .88$ & .14 & $0.17^{* *}$ & .06 & -0.10 & .22 & -0.09 & .09 & 0.25 & 0.28 & 0.26 \\
\hline \multicolumn{13}{|l|}{ Chaos } \\
\hline Control group & $2.60 \pm .77$ & $2.83 \pm .87$ & .23 & & & & & & & & & \\
\hline Intervention group & $2.70 \pm .65$ & $2.71 \pm .59$ & .01 & & & & & & & & & \\
\hline Total & $2.65 \pm .72$ & $2.77 \pm .83$ & .12 & $0.21^{* * *}$ & .05 & 0.15 & .18 & $-0.18^{*}$ & .01 & 0.17 & 0.26 & 0.18 \\
\hline
\end{tabular}

Note. $* p<.05, * * p<.01, * * * p<.001$ 
Table 5. Intervention effects from pretest to posttest for athletes' reported autonomous motivation, controlled motivation and engagement.

\begin{tabular}{|c|c|c|c|c|c|c|c|c|c|c|c|c|}
\hline & \multicolumn{3}{|c|}{ Descriptives } & \multicolumn{6}{|c|}{ Fixed Effects } & \multicolumn{3}{|c|}{ Random Effects } \\
\hline & \multirow[t]{2}{*}{$\begin{array}{l}\text { Pretest } \\
M(S D)\end{array}$} & \multirow[t]{2}{*}{$\begin{array}{l}\text { Posttest } \\
M(S D)\end{array}$} & \multirow[t]{2}{*}{$\Delta$} & \multicolumn{2}{|c|}{ Time } & \multicolumn{2}{|c|}{ Condition } & \multicolumn{2}{|c|}{$\begin{array}{c}\text { Time } \mathrm{x} \\
\text { Condition }\end{array}$} & \multirow[t]{2}{*}{ Residual } & \multirow[t]{2}{*}{$\begin{array}{l}\text { Level } 2 \\
\text { intercept }\end{array}$} & \multirow[t]{2}{*}{$\begin{array}{l}\text { Level } 3 \\
\text { intercept }\end{array}$} \\
\hline & & & & $\beta$ & $S E$ & $\beta$ & $S E$ & $\beta$ & $S E$ & & & \\
\hline \multicolumn{13}{|l|}{$\begin{array}{l}\text { Autonomous } \\
\text { motivation }\end{array}$} \\
\hline Control group & $5.81 \pm .81$ & $5.64 \pm .86$ & -.17 & & & & & & & & & \\
\hline Intervention group & $5.70 \pm .85$ & $5.87 \pm .84$ & .17 & & & & & & & & & \\
\hline Total & $5.76 \pm .83$ & $5.75 \pm .86$ & -.01 & $-0.15^{*}$ & .06 & -0.32 & .17 & $0.30^{* * *}$ & .09 & 0.26 & 0.38 & 0.08 \\
\hline \multicolumn{13}{|l|}{$\begin{array}{l}\text { Controlled } \\
\text { Motivation }\end{array}$} \\
\hline Control group & $3.39 \pm 1.05$ & $3.39 \pm 1.23$ & .00 & & & & & & & & & \\
\hline Intervention group & $3.38 \pm .98$ & $3.32 \pm 1.16$ & -.06 & & & & & & & & & \\
\hline Total & $3.39 \pm 1.01$ & $3.36 \pm 1.19$ & -.03 & 0.01 & .08 & 0.06 & .21 & -0.05 & .12 & 0.43 & 0.72 & 0.06 \\
\hline \multicolumn{13}{|l|}{ Engagement } \\
\hline Control group & $5.39 \pm .89$ & $5.31 \pm .95$ & -.08 & & & & & & & & & \\
\hline Intervention group & $5.22 \pm .81$ & $5.48 \pm .81$ & .26 & & & & & & & & & \\
\hline Total & $5.31 \pm .85$ & $5.39 \pm .89$ & .08 & -0.07 & .06 & $-.43^{*}$ & .19 & $0.33^{* * *}$ & .08 & 0.22 & 0.42 & 0.15 \\
\hline
\end{tabular}

